Article

\title{
Processes of Participation in the Development of Urban Food Strategies: A Comparative Assessment of Exeter and Eindhoven
}

\author{
Aniek Hebinck ${ }^{1,2, *}$ and Daphne Page ${ }^{3}$ \\ 1 Stockholm Resilience Centre, Stockholm University, Stockholm SE-106 91, Sweden \\ 2 Rural Sociology Group, Wageningen University, Wageningen 6708 PB, The Netherlands \\ 3 Centre for Food Policy, City University London, London EC1V 0HB, UK; daphne.page@city.ac.uk \\ * Correspondence: aniek.hebinck@su.se \\ Academic Editor: Han Wiskerke
}

Received: 14 April 2017; Accepted: 31 May 2017; Published: 2 June 2017

\begin{abstract}
Urban food strategies are increasingly being used as means to address a multitude of challenges presented by food system failings. The use of participatory approaches has become common practice in the field of urban food systems planning. These approaches are believed to democratize, legitimize and increase effectiveness of addressing challenges. Despite these "promises", they have also been viewed as problematic for being unbalanced and lacking accountability. This paper sets out to compare the creation and use of new participatory spaces in two initiatives in two European cities in their on-going attempts to formulate urban food strategies through multi-actor processes. This is explored through operationalisation of two key concepts essential to participatory approaches: participation and accountability. As such, the paper addresses how participatory processes for urban food strategies can be conceptualised when policy making involves the interplay of actors, knowledges and spaces. We conclude that within the two cases, ample attention is given to get a cross-section of the types of participants involved, while accountability is an aspect still under-represented. Based on the two cases, we argue that incorporation of accountability in particular will be instrumental in the development and implementation of more mature urban food strategies. However, it is essential for participatory processes to not completely break from more "traditional" policy processes, at risk of limiting progress in strategy development and deployment.
\end{abstract}

Keywords: participatory processes; urban food strategies; accountability; food policy

\section{Introduction}

Urban Food Strategies have become regarded as a pivotal point of change in addressing food systems failings and transitioning to sustainable food systems at the local level [1-5]. Food systems refer to the "web[s] of actors, processes, and interactions involved in growing, processing, distributing, consuming, and disposing of foods" [6] and their principal aim is to deliver sustainable food security [7-9]. Many food systems fail to do so and present concerns to stakeholders, such as the associated challenges of degradation of ecosystems [10], growing inequalities [11] and resource use $[6-8,12]$. The city region is increasingly identified as the appropriate level for action "to develop and implement an integrated and comprehensive solution for a future-proof urban food system" [4,12-14]. The city region is a spatial representation that allows to look beyond cities' administrative boundaries $[13,14]$, in the sense that it takes into account a single urban centre or multiple urban centres and the peri-urban and rural hinterlands that surround them. Cities have become powerful actors in addressing societal problems, as it is argued they can have more impact than nation-states [15-20]. Firstly, due to urbanization rates and economic concentration, the "generative 
powers" of cities have become "world-making" [15,18]. ("World-making" in the sense that cities have become the sites where power, knowledge, culture, etc. are most concentrated. Only a handful of cities now "drive world economic growth" [15]). Secondly, city-level governors can prioritize local challenges more effectively than state-level government because they are embedded in their locality, often dealing with daily problems in innovative and bespoke ways. Thirdly, while the state is known for being a slow apparatus having to deal with international relations, cities are primarily concerned with urban dynamics and just "have to get things done" [16,21]. The willingness of cities to take action is visible in the increasing number of urban strategies being developed all over the world. One reason for this being that "UFSs aim to place food on the urban agenda, capitalizing on efforts made by existing actors and creating synergistic effects by linking different stakeholder groups" [22]. Through a community-based food systems approach themes that typically overlap and link to various municipal departmental mandates — such as food security, public health, and social justice — can be addressed effectively $[22,23]$. Such policy tools can take on various forms, including food charters, food strategies, and food action plans $[23,24]$. These can be local or regional and would ideally be a part of local comprehensive plans and policies with touch points to the local food system. Local policies must reflect their unique local contexts [25] and incorporate "[h]istorical and cultural factors, ... geographical setting and natural resources ... and societal and political factors" [22]. These in turn will shape the "aims, objectives and actions that are appropriate and achievable" for a UFS [22].

Such a shift toward more inclusive policy making at this local level thus requires policy tools that can open up and democratize key policy tasks. Policy-making itself is "the interplay of actors, knowledge and policy spaces [which] is clearly dynamic and complex" [26]. Participatory approaches in particular frequently emerge as new forms of policy-making that reconfigure these elements and allow for incorporation of a broader range of policy actors (or "stakeholders"). This offers policy based on multiple dimensions of knowledge, and shapes a policy space that differs from those traditionally used. The use of participatory approaches in urban food policy-making is promising $[6,22,27,28]$ —ince it is said to lead to increased legitimization, effectiveness, and democratization of planning [29,30], but requires critical review in terms of what conceptualises the participatory processes.

Based on experiences gathered from two research projects, this paper aims to review participatory processes that contribute to the formulation of UFSs. The question this paper addresses: How can participatory processes for UFSs be conceptualised when policy making is the interplay of actors, knowledges and spaces? We do this by interrogating two cases; first, that of the Exeter Food Network, a member of the UK's Sustainable Food Cities Network, and the second being Proeftuin040 in Eindhoven in the Netherlands. We start by reviewing some of the literature on participation, to get an idea of its origin and to clarify some key concepts which will lead to a conceptual framework. Following this, we give brief descriptions of the two case studies in order to provide context, considering the different institutional structures of the local food groups, and the unique interplay of actors and local food system objectives. We then turn to the analysis, which will highlight how participation and accountability are manifested within the participatory processes of the two cases. This will lead to the conclusion that the elements that are key to making participatory processes successful are often neglected in light of the messy local governance process that includes stakeholders that are not normally engaged in policy-making or decision-making.

\section{Participation}

In this section, we first interrogate two strands of literature describing a turn towards participation and how this has shaped and constructed contemporary processes of policy-making and sustainable development. This literature provides the basis for a conceptual framework for the analysis of participation and multi-stakeholder processes.

Firstly, at the foundation of the use of participatory approaches in sustainable development practices lies a critique of discourses on modernity [31-34] which were central to the "early" field of International Development. This gave rise to a vast field of research that aimed to go beyond "western 
trajectories of modernity" and emphasised the value of "local knowledge", "counter-development (i.e., strategic actions that counter the dominant development trends and thinking [31])", and "bottom-up participation" [31,35,36]. Participatory approaches were argued to make development more "responsive to citizen desires and more effective in service delivery" [37] and would allow for local people to make sense of, interpret and shape policies and development programmes the way they see fit $[31,38]$. As such it was an explicit attempt to move beyond expert-driven policy-making $[34,39,40]$ that often offers little space for "local knowledges". The underlying logic is that the gap between citizens and institutions can be bridged by giving space to citizens or locals to exercise voice and influence policy and institutions [41,42]. As such, it is an attempt to balance "bureaucratic procedures and local practices" [31].

A second strand of literature is focussed on participation as a remedy for democratic deficits in (global) governance. "Governance has become post-sovereign, in the sense that policy processes are institutionally diffuse and lack a single locus of supreme, absolute and comprehensive authority. Today no regulatory body-including a state—constructs public policy on its own" $[43,44]$. Sources of legitimacy and accountability in policy-making shift with the arrival of these new actors and many such arrangements have "been found to suffer from democratic deficits" [29]. This is partly due to two large groups of actors that gained considerable importance in global governance arenas. Firstly, corporations are now often consulted during policy development. Their participation in processes of governance is greatly contested; some see them as "engines of growth", while others find them responsible for increasing levels of poverty [45-48]. Secondly, Civil Society Organisations (CSOs) have gained influence in global governance [43,45,49,50]. (Civil Society is here defined as "a political arena where associations of citizens seek, from outside political parties, to shape societal rules" [43], as such this may include NGOs, social movements, people's organisations and so on; for an overview of the complexity and diversity of civil society, see, e.g., Scholte [43] and Willets [45]) CSOs are "presumed to be closer to 'the people'" and increasingly have played an important role in "delivering development assistance" [51]. Considering both actors have gained considerable influence in societal and economic terms, their inclusion in governance processes is meant to lead to more effective and democratic policies. At national levels, there is increasingly talk about the need to give space for participation in governance (in the U.K., this discussion is dubbed "Big Society", while in the Netherlands this is referred to as "Participation Society"). In the Global South, there are already plenty of examples of citizens' participation in local governance, such as citizens' forums in Indonesia and neighbourhood meetings in Porto Alegre [30]. Increasingly, in the Global North the involvement of "active citizens" is seen as key for wellbeing [52,53]. This is supported by the understanding that involvement of citizens in such processes "makes for better citizens, better ... decisions and better government" [51,54]. However, it can also be explained by the neoliberal tendencies of many states, which are rolling back their welfare policies and calling upon citizens and third sector to assume more responsibilities [52,55].

We can conclude from the literature that moves to participatory approaches are based on democratic principles. Participation of stakeholders is seen as a method to balance the power that was previously largely assigned to states [56], allow citizens to shape and construct their opportunities and rules [51], and for poverty reduction [37]. In reality, this is infinitely more complex. Critics emphasise concerns around "wishful thinking" and "bad practices" in the implementation of participatory approaches, such as "use of the label without the substance"; "putting methods before process of empowerment"; and exclusion of the poorest [35,57]. It is often emphasised that the term has become a buzzword that is inherently vague and is used for multiple ends: "'[P]articipation' has historically been used both to enable ordinary people to gain political agency and as a means of maintaining relations of rule for neutralising political opposition" [35]. These concerns emphasise the necessity to safeguard key democratic values in these processes. A large portion of the literature on participatory processes is concerned with the evaluation of two key values, participation and accountability $[29,41,43]$. As stakeholders get space within agenda setting and policy making, key values that are often underlined include: enhancement of democratic legitimacy; potential to strengthen 
external accountability; increased effectiveness and quality; more adaptability and creativity; and greater responsiveness $[37,43]$. They are considered essential in securing the benefits of participatory decision-making, in contrast to state-centred decision making. There are a number of specific challenges related to the prevention of "bad practices" in participatory processes. Many of these challenges also relate to safeguarding accountability and participation: "retooling" (adapting to the new form of rulemaking), "negotiating cultural diversity", "securing compliance", "obtaining accountability", and "fostering access" (of information and resources) [43]. It is clear that the design of the multi-stakeholder approach becomes equally important as the behaviour and attitudes of the actors involved. There are numerous ways to design the involvement of these non-governmental stakeholders in governance structures, depending on the context, involved parties, objectives, and so on [58].

\section{Operationalizing Participatory Policy Processes}

We will now highlight our conceptual framework by operationalising the two elements highlighted in the literature as key to the functioning of participatory approaches: participation and accountability (see Figure 1). These are found at the intersection of actors, knowledge and policy spaces; where policy processes take place [26]. Although we have established the concept of participation is subject to contestation, we turn to Polk and Knutsson [53] who distinguish between the "types of participants and their relationships to one and another" and "quality of participation in the participatory process". The first links clearly to representation: are "those that hold a stake" invited to the table? This is important to review considering this a major source of legitimization of such processes. The latter links to the access and space present stakeholders receive during the decision-making process and whether they are able to go beyond "superficial interactions" [53]. This partly relates to the power imbalances that may naturally be present, due to social (or cultural) hierarchies, but also to interests and mandates people might have. Through "incorporation through collaboration" [53] and the creation of a "safe space" [59] for all participants, more effective and democratic decision-making can be established.

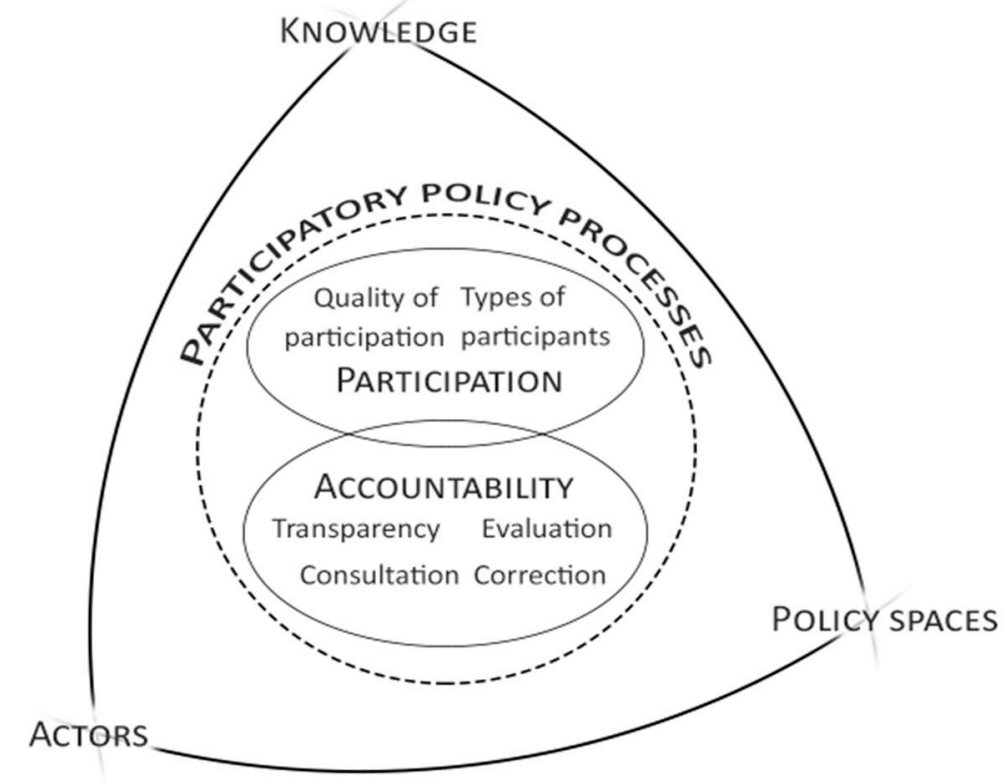

Figure 1. Conceptual framework operationalizing participation and accountability within participatory governance. Drawn based on the readings from Scholte, Polk and Knutsson and McGee [26,43,53].

In local (multi-stakeholder) governance, few links have been made to accountability, considering this is something that was mostly associated with states and government representatives. However, in an increasingly "post-sovereign" and multi-stakeholder context accountability—or the "processes 
whereby an actor answers for its conduct to those whom it affects" - does not just apply to states [43]. Rather, "accountability needs to be understood and practised in contemporary governance in a dispersed and shared fashion. All nodes in a given public policy network ... must play their part in delivering accountability" [43]. As such we argue accountability is also an important element in order to secure the promises of participatory governance when reviewing local governance arrangements, especially when accountability is regarded as a "means to constrain power" and to be responsive to the governed [37,43]. In examining the concept of accountability, Scholte [43] highlights four principal aspects: transparency on actions and used resources; consultation of those that are about to be affected; evaluation of impacts and effects; and correction in case actions have had harmful effects. According to Blair [37] there are multiple "mechanisms that can serve as agents of accountability" in local governance, such as elections, political parties, civil society, the media, public meetings, formal procedures, and opinion surveys. A number of these mechanisms, depending on the context and resources available, can be used to hold those that govern accountable.

These two concepts allow us to critically review the participatory processes that are part of the urban food strategy development in Exeter and Eindhoven. See Figure 1 for an overview of how these multiple mechanisms align on the intersection of knowledge, actors and policy spaces. This allows us to address the question: How can participatory processes for UFSs be conceptualised when policy making is the interplay of actors, knowledges and spaces?

\section{Methods}

This paper came out of a discussion where the authors found that they shared overlapping experiences of observing policy development in their respective cities. This prompted a preliminary review of elements common to each, or ways that these cities differed. Of particular interest was how and why the policy development process was initiated, which local players were involved, and how the creation of the documents was being executed. The similar, yet unique elements of each case suggested the potential for comparative analysis. The two cases have been independently researched by the authors, who have been participant observers of the multi-stakeholder meetings that were part of these urban food strategy developments. The case of Proeftuin040 in Eindhoven was part of the EU-project TRANSMANGO, as one of the Dutch local cases on "local" pathways to food and nutrition security (see Hebinck and Villarreal [60] for the full report). Exeter has been studied as a part of the PhD research being undertaken by Daphne Page at City University London's Centre for Food Policy. Interviews and document-analysis have been used to supplement observation and develop deeper understanding of the motivations of particular participants and institutional dynamics.

For the Exeter case study, the researcher was invited by the steering group convenor to observe the development process of the UFS, and consent to observe the process was granted by the steering committee on behalf of the broader Exeter Food Network (EFN). Observation, both in person and through inclusion in digital correspondence of the EFN activities and meetings, took place from summer 2016 and is still on-going at the time of writing. During observation, all participants were informed of the role of the researcher and that observation of the process would be taking place, and were given to opportunity to express any objections. There were no objections to the researcher's presence at any time, nor were any questions about the research process raised. This process involved attending EFN meetings, reviewing minutes of meetings to capture the details of discussions and plans surrounding the UFS, and attending the initial planning workshop. Data collection involved note taking throughout these events, and a desk analysis of minutes and documents to review for content pertaining to the UFS process.

For the second case in Eindhoven, the author had been pointed to the Urban Agriculture visioning process by an urban agriculture initiative that was part of exploratory research. She contacted Proeftuin040 about possible involvement of the project TRANSMANGO. From here on, Proeftuin040, the author and a project colleague who specialises in foresight methods had two meetings to discuss whether collaboration was wanted and what both parties were hoping to get out of it. During this 
meeting and all the following sessions, the role of the researchers was made clear to participants and in (public) reports of these meetings. The researchers attended meetings, arranged expert-consultation meetings and facilitated a number of sessions using foresight methods. The data used in this paper are based on those participatory encounters and reports written by Proeftuin040. For this paper, each case study was analysed according to the framework described above, and the authors compared findings based on their observations and experiences within the UFS development processes.

In both urban food strategy development processes foresight methods had been used as tools to "engage with complex challenges, and to mobilize action" [61]. In this they acknowledge future uncertainties, and together with a multi-scale, multi-actor group explore diverse possible future scenarios, without being held back by contemporary constraints or claims. There are many different foresight methods that all have a particular objective. In the case of Proeftuin040, "the seeds game", back casting and scenario-modelling were employed to help people to start thinking in new ways of the future. In Exeter, back casting in particular was used to envision more sustainable food systems in Exeter, and necessary steps to achieve these.

\section{Results}

\subsection{The Exeter Food Network}

Exeter, with a population of little over 124,000 in 2014 [62], is the main urban centre in Devon, a predominantly rural county in the southeast of England. Devon is a significant producer of agricultural products with a strong local food economy [63]. (According to 2008 figures [63], Devon's food economy (broadly, including restaurants, bars, supermarkets and accommodation) was measured at around $13 \%$ of Gross Value Added (GVA)—making it significantly higher than the same figure for Great Britain overall at 7.6\%). The strategy development process initiated in 2016 by the Exeter Food Network was an outcome of the earlier strategy experience in Devon in 2012. The Exeter Food Network was formed as a result of the Feeding Devon's Future strategy, and has sought to develop a more urban-focused document to address the city's unique needs, in contrast to the broadly rural and county-wide focus of the Devon strategy. An early EFN action was to join the Sustainable Food Cities Network.

Motivations behind the development of the Devon strategy differed between the civil society actors (concerned primarily with food poverty, waste, and ecology), and the council actors involved (focusing on the rural agricultural economy). As such, the Exeter effort sought to take a more urban focus to meet the needs of the city, rather than the previous county-wide approach, and to approach the process using the six key issues highlighted by the Sustainable Food Cities Network (these key issues are: (1) promoting healthy and sustainable food to the public; (2) tackling food poverty, diet-related ill health and access to affordable healthy food; (3) building community food knowledge, skills, resources and projects; (4) promoting a vibrant and diverse sustainable food economy; (5) transforming catering and food procurement; and (6) reducing waste and the ecological footprint of the food system. More information on these key issues is available on www.sustainablefoodcities.org/keyissues), but with food poverty still a central issue. Resulting from the previous Devon strategy experience, and concerns over a climate of austerity (with its associated budget cuts in local councils) across England, a decision was made to establish the Exeter strategy process as a primarily grass-roots effort. This shaped the participation structure for the UFS as being the domain of the Exeter Food Network, rather than foster dependence on the Council. It was felt that this would allow for more control over the long-term delivery of projects and programs without fear of failure from council support being lost. This reflects Marsden and Franklin's [55] point that civil society is moving to fill the gaps left by government in regards to local-level social support.

Participation in the strategy development process is limited to members of the Exeter Food Network. This is a voluntary, civil society group with representation of about 20 organisations (and many individuals) is made up of a variety of local interest groups, small local businesses, and 
non-profits (www.exeterfoodnetwork.org.uk). Some council representation exists through links to the Public Health and Sustainability departments at the local council level, however, the effort is largely civil society driven, rather than a council initiative.

Several actors in the Exeter strategy development process had been involved with the earlier Devon process. Notably this includes the initiator of the Devon strategy, who has become a local (civil-society) leader for food system efforts in Devon and Exeter, and has acted as the Steering Group convenor for both. These actors bring the shared experience and network from the previous strategy process, local-specific knowledge, and awareness of local government mechanisms relating to local food system work. A quality that cannot be understated is a shared commitment to improving aspects of the local food system for the greater good of the city. However, despite these underlying social concerns, public consultation beyond the members of the EFN has not been a part of the process up to the current draft-writing stage of the strategy. The EFN chose to keep the UFS development process internal to the group, which allowed for efficient organising and decision-making.

The EFN process to date has involved facilitated workshops to define the priorities of the strategy using foresight methods, as well as updates from the Steering Committee on document progress, which were communicated during regular EFN meetings and emails to the group's mailing list. The Steering Group has played the primary role in drafting the strategy from content gathered in the EFN workshops, as well as the framework themes provided as guidance for policy makers by the SFCN. Throughout the draft stage (again, still on-going at the time of writing), priorities included local food poverty, community building through food, and encouraging healthy eating.

\subsection{Proeftuin040, Eindhoven}

The second case that focuses on the use and creation of participatory spaces is that of Proeftuin040 (PT40). This is a visioning-process aimed at the development of a municipal policy informed by citizens, and on-going urban agricultural practices that are able to support and facilitate these urban agriculture activities. Eindhoven is the fifth largest city of the Netherlands with approximately 224,000 inhabitants. It is located in the south of the country and was largely shaped by the multinational technology company Philips during times of industrialization which has instilled a culture of embracing technology as a solution to local level challenges. It still strongly defines the city region as being a hub for technology and design industries. The rural areas surrounding the city are mostly used for agricultural purposes, where industrial pig farming is one of the main economic activities. The city of Eindhoven had quietly seen a proliferation of urban food system initiatives. For that reason, a visioning process was initiated, as a way to capture these local dynamics for policy purposes. The council of the Eindhoven municipality had commissioned this participatory process to the urban agriculture platform PT40.

The platform PT40 (www.proeftuin040.nl) was initiated by two urban planners with ambitious ideas about the role of urban greening (i.e., vegetation, agriculture) in urban areas, and aims to "initiate, strengthen and embed" UA initiatives in Eindhoven. This is reflected in their name; "Proeftuin" stands for "experimental" or "tasting" garden in Dutch, and 040 represents the area code for Eindhoven. The platform was supported by a regular group of local stakeholders, who are consulted at least four times a year regarding urban agriculture in the city. From the onset, the platform had tried to gather support from UA initiatives by organizing UA activities in the city, such as the placement of beehives, and guerrilla gardening in key locations in the city. However, especially at the start of the vision-making the platform was not yet broadly established and for many UA stakeholders still unknown. Nevertheless, the municipality's wish to have a "city supported" vision on UA, already predetermined an open approach to participation in this process. This essentially meant that PT40's objective was to capture the views all possible stakeholders within the city of Eindhoven. On top of that, the construction of a vision on urban agriculture, or other forms of policy making, was not something PT40 had done before and as such a major assignment. 
Within this case-study three phases can be described: the process-planning phase in which PT40 and the municipality design the broader framework of the process and its objectives; the city consultation phase that included a number of workshops and presentations; and the eventual reporting by PT40 which required distillation of the gathered ideas and visions and writing up. In the next section the execution of accountability and participation will be described in terms of involvement of actors and process-practicalities within these phases.

\subsection{Comparison of Participatory Policy Processes}

Participatory policy processes are differently constructed in the two cases of urban food strategy development. By using the conceptual framework, which sets out accountability and participation as key elements in participatory policy processes, we can highlight what some of these differences are and how that shapes policy processes. Within the two cases we have underlined these elements of participatory policy processes and how they are embedded in the policy process according to McGee [26], taking consideration of actors, knowledge and policy spaces. In this section, we present the two cases to illustrate how the participatory policy processes differ. See Table 1 for a comparative overview. Although the principal aspects and what policy process elements they belong to are inseparable, for analytical purposes we have made a distinction, which is discussed below.

\subsubsection{Participation}

One of the key aspects of participation is the need to establish a group of participants that mirrors the types of people that hold a stake in the issue being dealt with. This partly legitimizes the process, for it suggests that the views of all stakeholders are incorporated in a certain policy process. Both cases show explicit, yet differing attempts to broaden the type of participants in the policy process. Participants from various disciplines and backgrounds are incorporated in both processes. However, in Exeter these were already part of the Exeter Food Network; as such the process was kept internal to the (largely civil society) group. This also means the participants already had prior associations with one another. Being an interest group in a small city, the EFN is a largely cooperative group of people who are familiar to one another as community members, colleagues, and acquaintances, with some having worked closely together from the previous experience of developing Devon's county food strategy. Development of the Devon strategy offered lessons, having revealed tensions between a largely civil society group working with few parameters to create a strategy on the council's behalf. This experience, the broad nature of the county-wide and mostly rural strategy, and the lack of reliable funding from council sources led to the EFN to focus its efforts on the urban realm and to be less outwardly reliant. In Eindhoven, the assignment was to capture "the city's vision". As such one of their priorities was to have a group of participants that could represent "the city". In reality, this proved difficult for PT40. A few bigger corporate actors, such as a big Dutch supermarket chain, had declined the invitation to the initial workshops, adding that they were interested in partaking in a later stage of the process. Secondly, while organisations that target certain vulnerable groups (e.g., social housing cooperation) were part of the process, open invitations did not yield any participants that belonged to the actual vulnerable group. Prior to the workshops, these organisations already collaborated with the municipality and experiences. The initiatives' actors were also on many accounts sceptical of the municipality and many thought it was too bureaucratic and not flexible enough. Moreover, although the process was initiated by the municipality, only few municipal policy makers participated in the process, leaving another important actors underrepresented. In the cases this makes for different starting points, as the one is kept within an existing network, while the other is starting a new network. Incorporation of vulnerable groups is a weak spot in both participant groups. Important for participatory policy processes is not only to invite the right people to the table, but also to get them to the table. 
Table 1. Comparison of key elements in participatory policy processes in the case of the Exeter Food Network and Proeftuin040.

Types of participants

and their relationships to on

and another

Quality of Participation

in the participatory proces
- Interdisciplinary group of actors, based on the EFN members: mostly civil society actors, small scale loca farmers, non-profit actors, volunteers, and some council representatives (Public Health, Sustainability);

- A civil-society-led effort, rather than council-initiated;

- Being a small city, this network of like-minded individuals were all known to one another. Most members had previous collaborative relationships;

- The core Steering Group was formed of several members reconvened from the 2012 Devon strategy process, with some new actors;

- No vulnerable groups included; only a "elite" group with specialist knowledge, some "representing" those vulnerable groups.
- Interdisciplinary group of actors: local and regional government, housing corporations, elderly care institutions, community centres, social welfare organizations, regional health authority, urban food initiatives, (small) retailers, landscape architects, design studios, and academics;

- Decline of (initial) participation by bigger corporate actors and only few municipal policy-makers who were involved from start to end:

- No vulnerable groups participated; only institutions or initiatives targeting or representing vulnerable groups;

- Majority of urban agriculture initiative actors had no prior collaborative relationships; The municipal institutions did, but on different themes: such as housing or care;

- High level of participation in the 1st workshops; decreasing numbers towards final ones.

- $\quad$ Leader: Local knowledge, particularly in food security and local poverty context, practical knowledge of local networks, previous strategy development experience;

- Foresight methods, on-going dialogue during EFN meetings, email updates to wider EFN group, significant role of Steering Group in strategy "leg work" (distilling meeting takeaways, structuring and writing of strategy);

- Creation of new policy spaces by using mixed expertise, and foresight methods

- Building on the Devon experience: lessons learned, more-grassroots in development and project

deployment, with a focus on reduced dependence on council supports.
- $\quad$ Structured workshops were used to discuss the future of UA, which provided a "safe space" that allowed for knowledge sharing among the different participants;

- Little time was given for participants to get acquainted with each-others' work in the first workshops; that distracted participants from the workshops' goals and objectives;

- In the final workshops that used foresight methods that allowed for free exploration of the future of UA. 
Table 1. Cont.

\begin{tabular}{|c|c|c|c|}
\hline & & The Exeter Food Network & Proeftuin040, Eindhoven \\
\hline \multirow{4}{*}{ Accountability } & $\begin{array}{l}\text { Transparency } \\
\text { on actions and used resources }\end{array}$ & $\begin{array}{l}\text { - Reference to the principles of SFCN as a framework; } \\
\text { Collaboration with select members of local council; } \\
\text { Little interaction with the broader public about UFS } \\
\text { development process or aims. }\end{array}$ & $\begin{array}{l}\text { - Public announcement of the municipal council } \\
\text { commissioned vision for UA; } \\
\text { - Used resources, dates of workshops and meeting } \\
\text { spaces openly available on PT040's website; } \\
\text { - Initial workshops were invitee only; based on PT040's } \\
\text { and municipal network. }\end{array}$ \\
\hline & $\begin{array}{l}\text { Consultation } \\
\text { of those that are about to } \\
\text { be affected }\end{array}$ & $\begin{array}{l}\text { - Steering Group meetings reported discussion of larger } \\
\text { - Lolitical dynamics (Brexit); } \\
\text { Local level expertise (knowledge of local food systems, } \\
\text { social issues, business, network actors); policy } \\
\text { knowledge and an understanding of council workings } \\
\text { and key contacts-EFN members "representing" } \\
\text { the public; } \\
\text { - Internal EFN consultation with members: No } \\
\text { consultation of broader public. }\end{array}$ & $\begin{array}{l}\text { - Consultation of "the city" before and after vision } \\
\text { development through a town hall model and online } \\
\text { consultation on results via the website; } \\
\text { Call for consultation was mostly responded to by "the } \\
\text { already converted" and thought UA was a } \\
\text { worthwhile cause. }\end{array}$ \\
\hline & $\begin{array}{l}\text { Evaluation } \\
\text { of impacts and effects }\end{array}$ & $\begin{array}{l}\text { - Internal evaluation of drafts while in the development } \\
\text { process, input given during workshops by } \\
\text { participating EFN members; } \\
\text { - No evaluation of impacts at the development stage. }\end{array}$ & $\begin{array}{l}\text { Early evaluation of the vision was done through } \\
\text { foresight methods within the workshop rounds; this } \\
\text { allowed for open value and claim free exploration; } \\
\text { - Only a few policy-makers were involved at this stage } \\
\text { of evaluation. }\end{array}$ \\
\hline & $\begin{array}{l}\text { Correction } \\
\text { when actions have had } \\
\text { harmful effects }\end{array}$ & $\begin{array}{l}\text { - The Exeter Strategy is an evolution of previous local } \\
\text { strategy efforts } \\
\text { The UFS development is a voluntary effort; } \\
\text { accountability measures are unclear; } \\
\text { - No specific consideration given to potential negative } \\
\text { impacts during the early strategy } \\
\text { development process. }\end{array}$ & $\begin{array}{l}\text { - Nobody was really championing the process outside } \\
\text { PT040, so little responsibility was felt outside PT040; } \\
\text { Themes and objectives were adapted according to } \\
\text { consultation input; } \\
\text { - Final version of vision was evaluated by the council } \\
\text { and eventually rejected. }\end{array}$ \\
\hline
\end{tabular}


Secondly, highlighted in the cases is the quality of participation: this describes the space the participants receive during the participatory policy process and whether this is a safe space to interact about a certain topic. In both cases, we have seen the exploration of new policy spaces, meaning that they attempt to go beyond "traditional" policy spaces where knowledge is purely evidence-based and expert driven. The use of foresight methods is one way of achieving this, as this is a tool that allows for new ways of generating knowledge. On top of that, it is argued that because the future holds no claims or relations, foresight offers a "safe space" in which actors from diverse backgrounds can interact. In Exeter, participants are largely driven by their own values, experiences, and concerns over a number of local issues, which they feel can be positively impacted by having a food strategy. These could be shared and expanded upon through the foresight process during workshops. Particularly interesting is that at first participants found thinking of the future difficult, but in most cases really got the hang of it and reported positively about this new way of thinking. Notable is the role of the process leader; he/she steers the process in a certain direction in which their own background often has a considerable influence. In Exeter, the convenor of the steering committee is regarded as a moral authority through his position with the local church, and a respected local champion for his history of work with community groups, and on local poverty (including food poverty) issues. Ultimately, the convenor oversees the process and is in a position to ensure that particular concerns are represented, including their own. In Eindhoven, this came to the fore in the sense that the process leader often was not satisfied with the ability to vision about the future of the city-which is a key characteristic for a planner. Secondly, they were also new to collaborating with the municipality. As such, much of the policy-making process was new to the process leaders too. Furthermore, one of the leaders left PT40 halfway through the UFS development. This slightly shifted the focus within the UFS, with a priority on themes around circular economy, as this was an interest of the leader that was now solely in charge.

Although both cases differ in their ways of ensuring participation of stakeholders, they are considerably different from traditional policy processes. The process in Exeter was limited to those within the established Exeter Food Network. As a civil-society partnership group made up of community members, the EFN seems to have taken on the role of "representing" groups in the community, albeit with little representation from vulnerable groups themselves. Rydin and Natarajan [64] described this as "empathetic understanding of other people's experience" that these actors had gained through their own grassroots contact with others, for example, those experiencing poverty, and as such "were speaking beyond their immediate experience and for a range of other people". Despite being largely homogenous in terms of class and ethnicity, it is diverse in the disciplines and professions represented at the table. In contrast, Eindhoven intended to provide ample space for a broad range of actors to participate, however was not sufficiently able to accommodate them within the process.

\subsubsection{Accountability}

Besides participation, accountability is key to the participatory policy processes. When accountability is safeguarded within the process, it is a way of constraining power and being responsive to those governed. This starts with transparency on actions and used resources in the policy processes. PT40 had been very clear about their collaboration with the municipality and the resources used during the process: the municipality had commissioned this vision and therefore was paying the bills. Moreover, the documents produced by PT40 were published on their website and disseminated further via social media. This also includes participant lists, minutes and agendas of workshops and meetings. To the people participating in the workshop, they made abundantly clear that what came out of this process needed to be acceptable to the municipal council. In Exeter, the process started by building on the strategy that was developed for Devon and earlier SFCN principles. However, during the policy process little was made public about proceedings, agendas, participants, and direction the UFS was heading in. Meeting agendas and minutes, as well as drafts of the strategy were shared by email to the EFN membership list, but not posted for the public online. One participant 
noted that the Exeter strategy initiative had a desire to foster a more empowered grassroots-led effort through the members of the EFN. This showed a contrast to the earlier Devon strategy, which was accountable to a council-heavy partnership group. As such we can conclude that both parties had rather different approaches to transparency in their policy processes; as transparency was high in Eindhoven in an attempt to connect to "the city", it was kept low in Exeter's policy process as it was focussed on an existing network.

A key aspect that follows being transparent, is consulting those that may be affected by your actions. Consultation clearly has overlaps with the key aspects that define participation, as it concerns hearing those that hold a stake. However, here we would like to focus on the types of knowledges that were consulted during the process. As McGee [26] argues, there are many different types of knowledges, embedded in different narratives and discourses, and giving space for these to encounter is essential for the establishment of legitimacy for a policy process. As emphasised above, not all of those affected were participating in UFS developments. In Exeter, the process was characterized by a small coalition with expert knowledge; comprised of people who have experience with various aspects of the food system, the local landscape (social, environmental and economic), and experience with policy making. In Eindhoven, this was rather different as they opened up the floor to practitioners, policy makers, planners, citizens, and academics. Although this makes for different types of knowledges, knowledge of vulnerable groups (other than an intended "representation" role through members) had not been included in either cases, even though both processes aim to affect these groups through their UFS-development. Furthermore, the absence of bigger corporate actors and a sufficient number of municipal policy makers meant a rather one-sided version of UA in the city was documented. In the case of Exeter, it was the membership with the Sustainable Food Cities Network that provided a framework of aims to draw upon which are being drawn upon throughout the network. Work in these areas can receive acknowledgment through the SFCN awards system, and in doing so projects the work of members to the broader network across the UK and Ireland.

Evaluation of the effects and impacts is essential to any policy process and usually takes place after the implementation of a certain policy. Considering this research has focussed on the actual policy processes that lead to UFSs, we explore the degree of evaluation within the policy process. In Exeter evaluation of the work delivered by the steering group was performed by the total EFN. A back-and-forth process organised by the convenor involved workshops with the EFN, drafting by the steering group using workshop feedback, and meetings for EFN review. In general, the evaluation was done with little interaction with the broader public throughout this drafting stage. In the case of PT40, the draft strategy was evaluated in a smaller foresight session and in a public town hall meeting. In the town hall meeting, stakeholders were giving the opportunity to highlight their concerns or issues with respect to the draft strategy. However, the people participating in this town hall meeting were largely the people who already were part of earlier meetings; only a few new actors took part in this exercise. A more detailed evaluation was done during the foresight workshop, where the strategy was "tested" by participants in various future scenarios. Especially this workshop resulted in a number of points that PT40 itself had not considered. Amongst other things, the need to rebrand the image of UA was stressed in order to make it mainstream in terms of language, and allow it to connect more to the municipality's perspective. While PT40 opened the space to the city during the evaluation of the draft, Exeter kept this process indoors. Nevertheless, PT40 was not able to reach a new public and relied mostly on the input of people that were already part of the process. In this sense, both relied on a like-minded core group of the already converted.

Correction involves a process for addressing and mediating potentially negative or harmful outcomes of actions relating to the strategy. In Exeter, the strategy was developed out of a perceived need to have more urban-focused effort to address Exeter's unique needs, rather than a county-wide and more rural document. This evolution process shows a form of correction from previous efforts. However, within the Exeter process, being a voluntary effort, the process has been primarily focused on addressing local issues and developing projects and programs. A systematic approach to evaluating 
potential negative outcomes and addressing them has not been made clear through the development stage, although with the EFN aiming to be a grassroots effort, it can be assumed that corrections will be the responsibility of the group, rather than an external body such as the council. Limited engagement with the broader community beyond the EFN may allow potential areas of concern to go unnoticed. At this stage, there has been no indication that the strategy will be formally adopted by the local council, resulting in it taking responsibility for the outcomes. Similarly, as a group, PT40 took ownership of the process, and so responsibility remained internal. While the UFS process was commissioned by the municipality, they made little effort to being accountable for the process. In fact, the municipality rejected the PT40's vision as they argued it was just "impossible for them to carry it out" (Personal communication, 2017). While the vision was based on the input of a group of engaged stakeholders, the municipality nonetheless chose to reject it, rather than correct it. Currently, PT40 has not been able to negotiate the next step in the UFS development process.

In both the UFS development processes, accountability was hardly (intentionally) embedded within the process design. While participation of different stakeholders was given ample attention, the aspects of evaluation and correction were not. In the case of Exeter, this may well play out as the strategy is developed beyond the early draft stages. The role of the EFN as a network supporting local level projects and programs over time, and involvement of the council, should it choose to formally adopt the strategy, are yet to be seen.

\section{Discussion}

The use of participatory policy processes is an attempt to break out of traditional forms of policy making [30,34,40]. Through the incorporation of the types of actors and knowledges related to the policy goal in question and the creation of new policy-spaces, new ways of policy making can be shaped that arguably are more democratic and effective [26]. The two cases show that when interrogating accountability and participation, participatory policy-making processes are differently shaped and conceptualised in the Exeter and Eindhoven cases. Reflecting on both cases with respect to the conceptual framework, we conclude that the combination of accountability and participation are crucial for the participatory policy process being able to provide a space for different types of actors to interact and shape effective policy as a result. Differences in the participatory policy processes are highlighted when focussing on the involved actors, knowledges, and policy spaces. Both cases paid specific attention to broadening participation within their policy-processes-Exeter within a confined "elite" group, and Eindhoven constrained by a limited number of recruited volunteer participants-whereas accountability was less addressed overall. Moreover, highlighted in the ultimate rejection of the Eindhoven UFS proposal is the complexity of participatory policy-making and the shaping of new policy spaces.

Firstly, we consider the former point, which emphasises how the idea behind participation becomes problematic: while PT40 had managed to include new knowledges and actors (such as local participants without prior experience in policy-making), their UFS was rejected by the city's council for not being feasible and too disconnected from their current policies. This strengthens the idea that policy is based on certain knowledge-networks and in particular favours the more empiric conception of "expert", or evidence-based knowledge [39,40]. The PT40 vision did not connect the grassroots local knowledges of participants to the more conventional "expert knowledges" that are prioritised within the local council's more conventional policy processes. Although during the evaluation phase, the need to mainstream the way of thinking about UA was emphasised, this was less reflected in the final vision, which was in many aspects highly progressive and in some points quite radical. As such, the municipality deemed the vision politically impossible to accept. This shows a disconnect in how knowledges are valued in policy making, and how essential it is to find a common language to communicate shared priorities. Furthermore, hardly any actors with experience in policy-making had been involved in the UFS-development, which would have contributed to the incorporation of "policy language" and "expert knowledge" from a government viewpoint. In the case of Exeter, 
however, a clear decision was made about limiting the scope of participation to those within the EFN in the development stage of the UFS, resulting in clear and efficient progress due to the small size and unimpeded focus of the group. Contrary to PT40, the EFN had a number of actors with previous experience in local food strategy development. This brought together local knowledge of issues and the food system, as well as an established understanding of council-level priorities that could provide "the hook" when framing strategy aims. This was helped along by a small number of council departmental staff involved, recognising a beneficial exchange through the partnership. Prior experience provided the EFN steering group in particular with a confidence to develop a grassroots driven UFS, as well as a pragmatic view with regard to council limitations, particularly in the face of budget cuts and the ability to contribute supporting resources to the strategy and its eventual deployment. This is illustrative of the "picking up the slack" activities of citizens at the local levels are taking on, where they feel councils are unable or unwilling to provide supports for local needs [52,55]. In the end, this structure contributed to a more effective policy process. This complicates the notion of participatory policy processes: while the use of participatory processes is clearly gaining popularity, there is still a clear need to connect to traditional policy-language and knowledge for the policy-process to be successful.

Secondly, with regard to the shaping of new policy spaces, the elements of participation and accountability show in both cases the lack of vulnerable groups being incorporated into otherwise collaborative processes. The two cases-studies both see UFSs as a means to address social inequalities and food insecurities, however, neither had managed to include these socially vulnerable groups at any stage in their policy-processes. Although Exeter had made the explicit choice of keeping the UFS-development internal in its draft stages, PT40 had extended open invitations to "the city" multiple times, which did not yield participants of these vulnerable groups. While the Eindhoven policy-process was pushing for the extreme in terms of participation by "the city", it was seemingly still too "closed down" [65]. It reflects a common issue in policy making of reaching vulnerable groups who are often least able to take time to volunteer and feel secure that there is the "safe space" [59] needed to share their voice. However, it also assumes that it is entirely clear who exactly are the stakeholders that will be affected by the policy in question. Some actors are not associated with the matter because of a lack of awareness, or through their own choice such as those who cannot justify giving up the time, while others might simply prefer to be excluded from the process [40].

Another common issue associated with participatory policy-processes is "participant-fatigue". Many of the multi-stakeholder processes we see at the local level, depend on the time and expertise of local, often voluntarily participating, actors. It takes a certain type of actor; one who feels sufficiently motivated and informed to work on a specific policy subject and to dedicate time to these processes in their free time. As such, the same actors are often called upon when a new multi-stakeholder process is initiated, for they are known as being open and capable of making a contribution. Due to the growing popularity of multi-actor approaches, these frequently-invited participants cultivate a certain participant-fatigue, making it harder for convenors to find a representative sample of stakeholders for the process. This may be particularly true at the local level where the pool of actors with both sufficient expertise and interest is limited. This was visible in the PT40 case, where the first workshops were highly successful in terms of their attendance rate and mix of stakeholders; but numbers dropped significantly towards the end of the process. While global, and sometimes also national, efforts at participatory policy-making often have budget to invite people; these small-scale and grassroots initiatives do not. Combining this with the previously mentioned lack of vulnerable groups within the participatory process, this clearly becomes a weak spot in terms of types of participation.

Relating to accountability, both cases show heavy reliance on the person championing the participatory policy-process. When the person championing this process is not experienced in policy-making, this proves problematic. In the case of the EFN, the leader of the process was well regarded for his previous policy and social work and was respected as an expert in local food and poverty matters. In this case, the authority granted to this individual by other participants had a positive influence on the outcome of the process. By comparison, the relatively "new kids on the 
block" PT40 was still in the process of establishing its own name as an organisation and also had little policy-making experience. This will have contributed to the disconnect with regard to the more conventionally used policy-language by the council and, arguably, the rejection of the vision in its entirety. Although Scholte outlines clearly some of the characteristics that make a good leader for such a process at a global governance level [43], we argue that further research is needed on what makes a good participatory process-leader at the local level. As both cases have shown these actors championing the process play a crucial role in connecting to the conventional ways of policy-making and reaching out to actors (from all levels), we feel that more empirical research on the matter will be able to establish more clear guidelines around the (potentially quite strategic) decisions surrounding the selection of such a leader.

Lastly, we argue that there is a need for more research around accountability on the local level. Considering most of the literature on accountability relates to global governance and especially on how to proceed from state-centred accountability to a multi-actor accountability context and how to evaluate and correct once the policy is implemented. As this research paper explored the process of development of UFSs, it meant we had to consider what accountability, and in particular evaluation and correction, mean during the developing of a policy. These aspects become especially relevant during and after implementation of a policy, thus we argue that they are vital to consider during the development of the process, and should not be regarded as "buffet style" choice options. Moreover, since local food strategies have become more common and moved into the domain of citizen-actors, the development of practical guides could offer valuable frameworks and tools to empower actors to integrate these elements into strategy processes and documents.

\section{Conclusions}

Urban challenges related to food, such as environmental change and food poverty, are growing. Urban food strategies have become regarded as a pivotal point of change to address said challenges. Considering this, this paper focussed on exploring what conceptualises participatory processes for UFSs. By operationalising participatory processes as elements of accountability and participation located at the interface of actors, knowledges and policy spaces, we have unpacked two cases of UFS development. We conclude that within the two cases, types of participants are given ample attention, while accountability is an aspect still under represented. Based on the two cases, we argue that the incorporation of accountability is especially instrumental in the development and implementation of urban food strategies. Each of the two cases offers a different participation model; Eindhoven attempted to develop a strategy out of transparent and inclusive process, but, in the end, was unsuccessful due to having not considered how best to integrate grassroots objectives into existing council plans and priorities. The EFN kept the process internal to the group in its early stages, and as a result was able to move efficiently through the UFS development. However, this approach may have compromised the process through excluding potentially valuable input from the public with interests and experience in key issues, such as food poverty. While both processes turned to UFS development as a step toward addressing local level issues, the two efforts represent two ends of a spectrum of participation; one very open, and the other one closed to wider public participation. Considering UFSs have huge potential in addressing food related urban challenges, we argue there is grounds for further empirical research on what constitutes a productive and representative strategy development process within that spectrum, tailored to local circumstances, needs and goals.

Acknowledgments: This paper is partly based on research from the project "Assessment of the impact of global drivers of change on Europe's food security" (TRANSMANGO), granted by the EU under 7th Framework Programme, theme KBBE.2013.2.5-01, Grant agreement No. 613532. Furthermore, the authors would like to thank the lecturers of the University of Oslo Centre for Development and the Environment PhD course on "Global food governance: the role of non-state actors" for their inspiring lectures and interaction that led to this paper. 
Author Contributions: Aniek Hebinck and Daphne Page participated equally in designing, analysing and writing the research article. The data the research is based on were collected as part of their individual research projects.

Conflicts of Interest: The authors declare no conflict of interest.

\section{References}

1. Hinrichs, C.C. Transitions to sustainability: A CHANGE in thinking about food systems change? Agric. Hum. Values 2014, 31, 143-155. [CrossRef]

2. Dubbeling, M.; Zeeuw, H.; Veenhuizen, R. Municipal Policies and Programmes on Urban Agriculture: Key Issues and Possible Courses of Action. In Cities, Poverty and Food: Multi-Stakeholder Policy and Planning in Urban Agriculture; De Zeeuw, H., Dubbeling, M., van Veenhuizen, R., Eds.; RUAF Foundation and Practical Action Publishers: Warwickshire, UK, 2011.

3. Prosperi, P.; Moragues-Faus, A.; Sonnino, R.; Devereux, C. Measuring Progress towards Sustainable Food Cities: Sustainability and Food Security Indicators; Report of the ESRC Financed Project "Enhancing the Impact of Sustainable Urban Food Strategies. Available online: http://sustainablefoodcities.org/Portals/4/ Documents/Measuring\%20progress\%20towards\%20sustainable\%20food\%20cities_final\%20report\%20w\% 20appendixes.pdf (accessed on 27 October 2016).

4. Morgan, K.J. Feeding the City: The Challenge of Urban Food Planning. Int. Plan. Stud. 2009, 14, 341-348. [CrossRef]

5. Pothukuchi, K.; Kaufman, J.L. Placing the food system on the urban agenda: The role of municipal institutions in food systems planning. Agric. Hum. Values 1999, 16, 213-224. [CrossRef]

6. IPES Food. The New Science of Sustainable Food Systems: Overcoming Barriers to Food Systems Reform; First Report of the International Panel of Experts on Sustainable Food Systems; The International Panel of Experts on Sustainable Food Systems (IPES Food): Brussels, Belgium, 2015.

7. Tendall, D.M.; Joerin, J.; Kopainsky, B.; Edwards, P.; Shreck, A.; Le, Q.B.; Kruetli, P.; Grant, M.; Six, J. Food system resilience: Defining the concept. Glob. Food Secur. 2015, 6, 17-23. [CrossRef]

8. Ericksen, P.J. What is the vulnerability of a food system to global environmental change? Ecol. Soc. 2008, 13, 14. [CrossRef]

9. Ingram, J. A food systems approach to researching food security and its interactions with global environmental change. Food Secur. 2011, 3, 417-431. [CrossRef]

10. Rockström, J.; Steffen, W.; Noone, K.; Persson, Å.; Stuart Chapin, F.; Lambin, E.F.; Lenton, T.M.; Scheffer, M.; Folke, C.; Schellnhuber, H.J.; et al. A safe operating space for humanity. Nature 2009, 461, 472-475. [CrossRef] [PubMed]

11. Food and Agriculture Organization of the United Nations (FAO). FAO Statistical Yearbook; Food and Agriculture Organization of the United Nations: Rome, Italy, 2012.

12. Wiskerke, J.S.C.C. Urban food systems. In Cities and Agriculture: Developing Resilient Urban Food Systems; De Zeeuw, H., Drechsel, P., Eds.; Routledge: London, UK, 2015; pp. 1-25.

13. Forster, T.; Escudero, A.G. City Regions as Landscapes for People, Food and Nature; EcoAgriculture Partners, on Behalf of the Landscapes for People, Food and Nature Initiative: Washington, DC, USA, 2014.

14. FAO; RUAF. A Vision for City Region Food Systems-Building Sustainable and Resilient City Regions; Food and Agriculture Organization of the United Nations: Rome, Italy, 2015.

15. Amin, A.; Thrift, N. Looking through the city. In Seeing Like a City; Amin, A., Thrift, N., Eds.; Polity Press: Cambridge, MA, USA, 2017.

16. Barber, B.R. If Mayors Ruled the World: Why Cities Can and Should Govern Globally and How They Already Do by; Yale University Press: London, UK, 2013.

17. McCormick, K.; Anderberg, S.; Coenen, L.; Neij, L. Advancing sustainable urban transformation. J. Clean. Prod. 2013, 50, 1-11. [CrossRef]

18. McKinsey Global Institute. Urban world: Mapping the economic power of cities. J. Monet. Econ. 2011, 36, 49.

19. Wolfram, M. Conceptualizing urban transformative capacity: A framework for research and policy. Cities 2016, 51, 121-130. [CrossRef]

20. The United Nations Educational, Scientific and Cultural Organization (UNESCO). Culture, Urban, Future-Global Report on Culture for Sustainable Urban Development; UNESCO Publishing: Paris, France, 2016. 
21. Milan Expo. Milan Urban Food Policy Pact; Food and Agriculture Organization of the United Nations: Milan, Italy, 2015.

22. Moragues, A.; Morgan, K.; Moschitz, H.; Neimane, I.; Nilsson, H.; Pinto, M.; Rohracher, H.; Ruiz, R.; Thuswald, M.; Tisenkopfs, T.; et al. Urban Food Strategies: The Rough Guide to Sustainable Food Systems; Foodlinks: Rochester, NY, USA, 2013.

23. Hodgson, K.; Campbell, M.C.; Bailkey, M. Urban Agriculture: Growing Healthy, Sustainable Places; American Planning Association: Chicago, IL, USA, 2011; pp. 1-145.

24. Sustainable Food Cities. Developing a Food Plan; Bristol City Council: Bristol, UK, 2013.

25. Cochrane, A.; Ward, K. Researching the geographies of policy mobility: Confronting the methodological challenges. Environ. Plan. A 2012, 44, 5-12. [CrossRef]

26. McGee, R. Unpacking Policy: Actors, Knowledge and Spaces. In Unpacking Policy: Knowledge, Actors, and Spaces in Poverty Reduction in Uganda and Nigeria; Brock, K., McGee, R., Gaventa, J., Eds.; Fountain Pub Ltd.: Amenia, NY, USA, 2004.

27. De Zeeuw, H.; Dubbeling, M. Process and tools for multi-stakeholder planning of the urban agro-food system. In Cities and Agriculture-Developing Resilient Urban Food Systems; De Zeeuw, H., Drechsel, P., Eds.; Routledge: London, UK, 2015; pp. 56-87.

28. Amerasinghe, P.; Cofie, O.O.; Larbi, T.O.; Drechsel, P. Facilitating Outcomes: Multi-Stakeholder Processes for Influencing Policy Change on Urban Agriculture in Selected West African and South Asian Cities; IWMI Research Report 153; International Water Management Institute (IWMI): Colombo, Sri Lanka, 2013.

29. Bexell, M.; Tallberg, J.; Uhlin, A. Democracy in global governance: The promises and pitfalls of transnational actors. Glob. Gov. 2010, 16, 81-101.

30. Gaventa, J. Strengthening Participatory Approaches to Local Governance: Learning the Lessons from Abroad. Natl. Civ. Rev. 2004, 93, 16-27. [CrossRef]

31. Arce, A.; Long, N. Anthropology, Development, and Modernities: Exploring Discourses, Counter-tendencies, and Violence; Routledge: London, UK, 2000.

32. Escobar, A. Encountering Development: The Making and Unmaking of the Third World; Princeton University Press: Princeton, NJ, USA, 1995.

33. Escobar, A. Displacement, development, and modernity in the Colombian Pacific. Int. Soc. Sci. J. 2003, 55, 157-167. [CrossRef]

34. Chambers, R. Whose Reality Counts? Putting the First Last, 2nd ed.; Intermediate Technology Publications: London, UK, 1997.

35. Cornwall, A.; Brock, K. What Do Buzzwords Do for Development Policy? A Critical Look at "Participation", "Empowerment" and "Poverty Reduction". Third World Q. 2005, 26, 1043-1060. [CrossRef]

36. Escobar, A. Territories of Difference: Place, Movements, Life, Redes; Duke University Press: Durham, NC, USA, 2008.

37. Blair, H. Participation and accountability at the periphery: Democratic local governance in six countries. World Dev. 2000, 28, 21-39. [CrossRef]

38. Blackburn, J.; Chambers, R.; Gaventa, J. Mainstreaming Participation in Development. In Making Development Work; Hanna, N., Picciotto, R., Eds.; Transaction: London, UK, 2002.

39. Cairney, P. The Politics of Evidence-Based Policy Making, 1st ed.; Palgrave MacMillan: Basingstoke, UK, 2016.

40. Cousins, B.; Hebinck, P. In the Shadow of Policy-Everyday Practices in South Africa's Land and Agrarian Reform; Wits University Press: Johannesburg, South Africa, 2013.

41. Gaventa, J. Exploring citizenship, participation and accountability. IDS Bull. 2000, 1-14. [CrossRef]

42. Baud, I.; Nainan, N. "Negotiated spaces" for representation in Mumbai: Ward committees, advanced locality management and the politics of middle-class activism. Environ. Urban. 2008, 20, 483-499. [CrossRef]

43. Scholte, J.A. Building Global Democracy? Civil Society and Accountable Global Governance; Cambridge University Press: Cambridge, MA, USA, 2011.

44. Barling, D.; Duncan, J. The dynamics of the contemporary governance of the world's food supply and the challenges of policy redirection. Food Secur. 2015, 7, 415-424. [CrossRef]

45. Willetts, P. Non-Governmental Organizations in World Politics: The Construction of Global Governance; Routledge: London, UK, 2011.

46. Clapp, J. Food, 2nd ed.; Polity Press: Cambridge, MA, USA, 2016. 
47. Van Der Ploeg, J.D. The food crisis, industrialized farming and the imperial regime. J. Agrar. Chang. 2010, 10, 98-106. [CrossRef]

48. Bäckstrand, K. Multi-stakeholder partnerships for sustainable development: Rethinking legitimacy, accountability and effectiveness. Eur. Environ. 2006, 16, 290-306. [CrossRef]

49. Duncan, J. Global Food Security Governance; Oxford University Press: Oxford, UK, 2015.

50. Warshawsky, D.N. Civil society and public-Private partnerships: Case study of the Agri-FoodBank in South Africa. Soc. Cult. Geogr. 2015, 17, 423-443. [CrossRef]

51. Cornwall, A. Locating citizen Participation. IDS Bull. 2002, 32, 49-58. [CrossRef]

52. Koster, M. Bridging the Gap in the Dutch Participation Society. Etnofoor Particip. 2014, 26, 48-64.

53. Polk, M.; Knutsson, P. Participation, value rationality and mutual learning in transdisciplinary knowledge production for sustainable development. Environ. Educ. Res. 2008, 14, 643-653. [CrossRef]

54. Mansbridge, J. On the Idea that Participation Makes Better Citizens. In Citizen Competence and Democratic Institutions; Elkin, S., Soltan, K.E., Eds.; The Pennsylvania State University Press: Pennsylvania, PA, USA, 1998.

55. Marsden, T.; Franklin, A. Replacing neoliberalism: Theoretical implications of the rise of local food movements. Local Environ. 2013, 18, 636-641. [CrossRef]

56. Dodds, F. The Context: Multi-stakeholder Processes and Global Governance. In Multi-stakeholder Processes for Governance and Sustainability; Hemmati, M., Ed.; Earthscan: London, UK, 2002.

57. Pijnenburg, B. Keeping It Vague: Discourses and Practices of Participation in Rural Mozambique. Ph.D. Thesis, Wageningen University, Wageningen, The Netherlands, 2004.

58. Hemmati, M. Multi-Stakeholder Processes for Governance and Sustainability; Earthscan: London, UK, 2002.

59. Pereira, L.; Karpouzoglou, T.; Doshi, S.; Frantzeskaki, N. Organising a safe space for navigating social-ecological transformations to sustainability. Int. J. Environ. Res. Public Health 2015, 12, 6027-6044. [CrossRef] [PubMed]

60. Hebinck, A.; Villarreal, G. "Local" level analysis of FNS pathways in the Netherlands: Two case studies, Urban Agricultural Initiatives and the Food Bank. TRANSMANGO: EU KBBE.2013.2.5-01 Grant Agreement No: 613532. 2016. Available online: http://transmango.eu/userfiles/update $\% 2009112016 /$ reports $/ 5 \%$ 20the\%20netherlands\%20report.pdf (accessed on 4 October 2016).

61. Vervoort, J.; Helfgott, A.; Lord, S. D3.2 Scenarios Methodology Framework and Training Guide. TRANSMANGO: EU KBBE.2013.2.5-01 Grant Agreement No: 613532. 2016. Available online: http: / www.transmango.eu/userfiles/update\%2009112016/transmango\%20d3.2\%20scenarios \% 20training\%20guide.pdf (accessed on 1 February 2017).

62. ONS. Population Estimates for UK Mid-2014 Analysis Tool; Office for National Statistics: Newport, UK, 2014.

63. Lobley, M.; Thomson, J.T.; Barr, D. A Review of Devon's Food Economy; CRPR Research Report No. 34; Centre for Rural Policy Research: Exeter, UK, 2012.

64. Rydin, Y.; Natarajan, L. The materiality of public participation: The case of community consultation on spatial planning for. Int. J. Justice Sustain. 2015, 21, 1243-1251.

65. Leach, M.; Scoones, I.; Stirling, A. Dynamic Sustainabilities: Technology, Environment, Social Justice; Earthscan: London, UK, 2010.

(C) 2017 by the authors. Licensee MDPI, Basel, Switzerland. This article is an open access article distributed under the terms and conditions of the Creative Commons Attribution (CC BY) license (http:/ / creativecommons.org/licenses/by/4.0/). 